Department of Health (1993) The Health of the Nation: Mental Illness Key Area Booklet. Heywood, Lancashire: BAPS Health Publications Unit.

FAlLOON, I. R. H. (1985) Family Management in Schizophrenia. Baltimore: John Hopkins University Press.
WiNG J. K. (1989) The concept of negative symptoms. British Journal of Psychiatry (Suppl. 7), 155, 10-14.

A full list of references is available on request to Dr Soni.

\title{
A community treatment order in practice
}

\author{
Toby Moate, Registrar in Psychiatry; Barbara Ward, Community Psychiatric Nurse; \\ and GWYN Evans, Consultant in Psychiatry, General Hospital, St Helier, \\ Jersey JE2 3QS
}

The Island of Jersey is a separate country from the United Kingdom and has its own laws. In the Jersey Mental Health Law, 1969, there is a community treatment order in which the guardian appointed has the powers of a father over a child (under 16). This law was implemented on 1 January 1972 and in this paper we look at the way in which it has been used in the 18 years between 1 January 1972 and 31 August 1990. We are not suggesting that the way in which we have used it has been the right or only way. We are engaged in description not prescription.

We have not found that the order gives rise to difficulties or controversy in practice. The guardian may act in a preventive manner and can intervene before a crisis develops. Incidentally, in the Jersey Law, the mentally handicapped patient is described as a "person requiring special care".

Between 1 January 1972 and 31 August 1990, 126 patients were placed under Guardianship Orders, and the patients were in five diagnostic categories: 31 patients needing special care; 31 patients with schizophrenia; 37 patients with dementia; 17 patients with alcoholism; and 10 patients with affective disorder, chiefly manic depression.

Most of the patients with alcoholism and manic depression under Article 21 willingly submitted to the order (the consultant usually promising to discontinue it if the patient, when well, so requested) because they themselves felt the need for some external control, seeing the havoc the illness was wreaking in their lives.

The order failed to achieve its purpose in 12 cases (one special care, four schizophrenic, three dementia, three alcoholic, and one affective) and was therefore discontinued.

The order was successful in achieving its purpose in 108 cases. The order was partly successful in six cases (all alcoholics who reduced but did not stop their drinking: the degree of improvement was judged worthwhile by all six patients and their families). In the successful cases it has often been possible to allow the order to lapse after a few years when new patterns of behaviour and habits have been established and good relationships with community nurses formed and consolidated. This has happened in seven cases in need of special care, six cases of schizophrenia, 22 cases of dementia, one case of alcoholism and seven cases of affective disorder.

So, this order has been found to be useful in $90 \%$ of cases for whom it was thought suitable, and it has been allowed to lapse, with preservation of the benefits gained, in $33.3 \%$.

Before giving case reports as examples it is necessary to point out limitations of the order, particularly its use for the administration of medication to schizophrenic patients who, from previous experience, would not otherwise take medication. The typical patient is on depot antipsychotic drugs and, at the time of his first refusal of an injection, will usually be mentally too well to justify admission under an order; in Jersey, the community psychiatric nurse (CPN) faced with this situation, reminds the patient of the existence of the order (which will have been clearly explained at the time of its inception) and points out that continued refusal will almost certainly lead to readmission and re-establishment of medication: the CPN makes no effort or threat to force the patient to have the injection or to readmit immediately. In the elegant phrase of our nurse author "the order is used to enhance and reinforce the ability of the nurse to persuade". It is obvious that much depends on the community nurse. The existence of an order does not prevent the forming of a good relationship as can be seen daily in any well-run admission ward.

If the nurse is unsuccessful in persuasion then, as in the UK, we have to wait until a crisis develops to remove the patient to hospital forcibly: in such a 
patient the order has failed in its purpose and is discontinued. The failure rate is low (four out of 31 schizophrenic patients): we see no solution for this group of patients: we do not and would not wish to live in a society in which apparently well patients (in the interval between their first refusal of medication and their overt clinical relapse) can be carried off struggling and protesting to their local hospital by "men in white coats".

\section{Case reports}

(a) A schizophrenic lady, aged 45, spent most of her life between the ages of 14 and 34 in hospital. Discharges were short lived, as she always stopped her medication on discharge, and readmission was invariably accompanied by violence. After discussion and explanation she was placed under a guardianship order and afterwards accepted intramuscular injections with mild verbal, but no physical, resistance. After two or three years she learnt that life was better on medication (although she still did not accept that she was ill) and the order was allowed to lapse. In the 11 years since the order was instituted there have been two very brief readmissions, both voluntary, and no episodes of violence.

(b) A 58-year-old alcoholic man (alcoholism, per se, can constitute grounds for compulsory orders under the Jersey Law, a provision which is almost useless except in this case and a few others like him) whose drinking was jeopardising his business, his marriage, and his liberty, agreed to be placed under a guardianship order after his third (voluntary) admission for withdrawal. Knowing that his wife has the legal right to have him readmitted at any time powerfully reinforces his own efforts at self-control and his drinking has been moderate by previous standards since with great benefit to his business and his marriage. He asks for renewal when the order runs out of time.

(c) A 45-year old manic depressive man had very acute upswings. On the first day of relapse his wife, and only his wife, would notice the mood change. On the second day he became grandiose, overactive, interfering and, if crossed, violent, putting at risk his marriage and his job. After his third admission he agreed to be placed under guardianship and the only subsequent relapse was dealt with by admission - against his wishes but with no violence - on the first day. This order has now lapsed because of successful control with medication.

(d) A 27-year-old man with learning difficulties became "addicted" to visiting doctors (all GPs in Jersey are in private practice) with a wide variety of physical symptoms and collected a vast number of tablets, and we feared he was distributing these generously to his friends. Once he was under a guardianship order we were able to stop this.

(e) The order is quite often used as a legal basis for the necessary control of wandering demented patients in homes for the elderly. The order is usually allowed to lapse once the patient has settled in.

\section{Conclusion}

We feel that a community treatment order leads to very few difficulties in practice and is of benefit to patients.

\section{Acknowledgements}

We wish to thank our consultant colleagues Dr John Fogarty and Dr Farouq Faiz for allowing us to report on their patients.

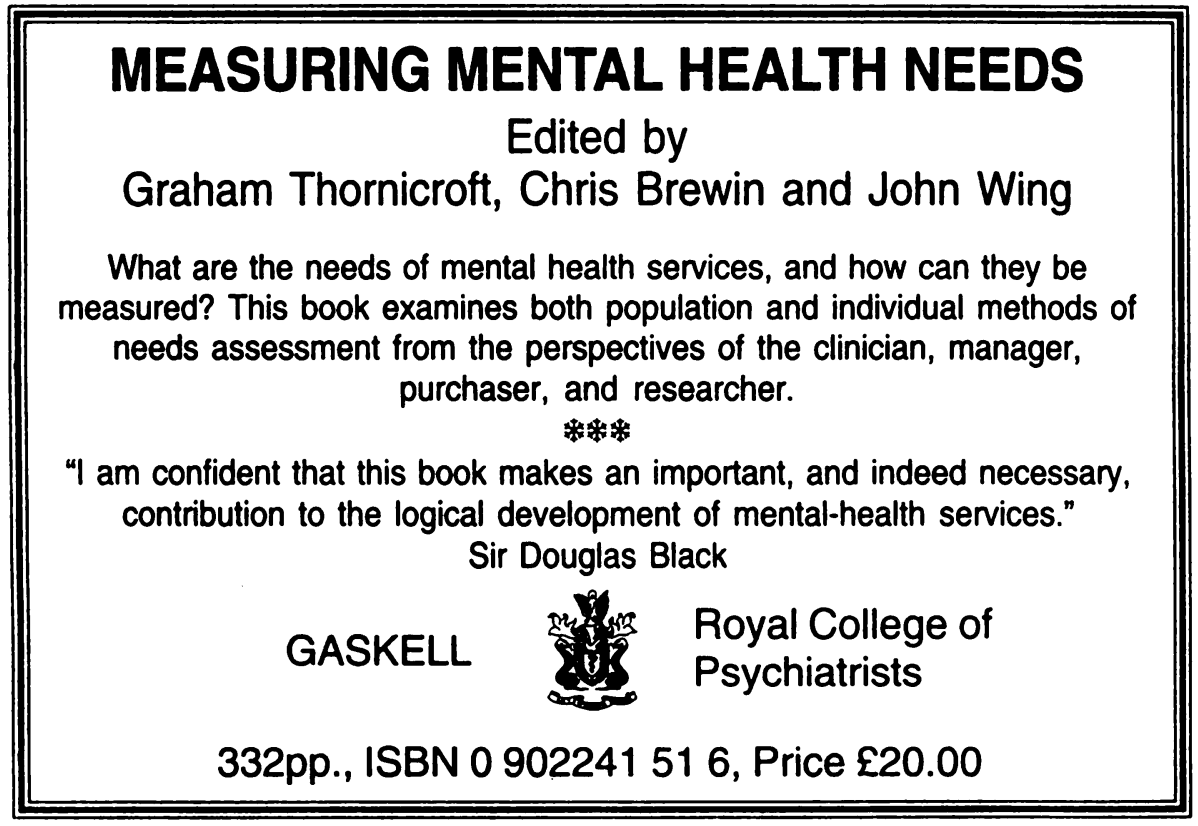

